\section{REFLECTIVE PRACTICE What is the role of academic institutions for the future development of Six Sigma?}

Jiju Antony

Centre for Research in Six Sigma and Process Excellence, Strathclyde Institute for Operations Management, University of Strathclyde, Glasgow, UK

\begin{abstract}
Purpose - This paper aims to present the role that leading engineering and business schools will play for the future development of Six Sigma.

Design/methodology/approach - This is a viewpoint article and the material presented in this article is based on the author's experience in the field of Six Sigma.

Findings - The findings of the paper reflect some of the major limitations of Six Sigma and the paper makes an attempt to address the importance of academic institutions to engage in Six Sigma research topics.

Research limitations/implications - The points expressed in this paper are based on the author's experience. It is essential to collect data on this topic from a number of leading researchers and practitioners in the field and to set out a research agenda in the future.

Originality/value - This paper provides an excellent resource for those people who are currently carrying out research in Six Sigma. Moreover, the paper is equally useful to practitioners to understand the major limitations of this powerful business strategy and the role of academic institutions to address these limitations in the future.
\end{abstract}

Keywords Quality, Six sigma, Process management

Paper type Viewpoint

Six Sigma is a highly disciplined, customer-oriented and bottom-line driven business improvement strategy that relies on statistical methods to make dramatic reductions in defect rates in processes; manufacturing, service or transactional. Organisations that implement Six Sigma have benefited from it in three major ways: reduced defect rate; reduced operational costs; and increased value for both customers and shareholders. Six sigma has been sweeping the business world with remarkable results over the last 20 years or so. It is now more than hype; it is a recognized methodology for solving process and quality related problems in modern organizations. As a Six Sigma practitioner and a researcher in the field of quality engineering and management, I have personally observed over a period of time that six sigma is not widely accepted by many academics in leading business and engineering schools across Europe. In many engineering and business curricula, statistical and non-statistical tools and techniques such as design of experiments (DoE), Taguchi methods (TMe), statistical process control (SPC), quality function deployment (QFD), failure mode and effect analysis (FMEA), seven tools of quality, etc. are often taught as standalone packages. I think the
Academic institutions 
IJPPM

57,1

108 six sigma framework can provide an excellent platform for integrating all the above tools and techniques into the curricula of engineering and business schools. Students in academic institutions will be exposed to real-world problems and cases. Many students in engineering and business schools do not appreciate the true value of practically useful quality and process improvement tools which require statistical skills and expertise. I think academic institutions can certainly offer low cost solutions to many burning problems in the industrial world by utilizing the best-in-class practice of six sigma and lean methodologies. Organisations can save several thousands of pounds (in small companies) and several millions of pounds (in the case of big corporations) on the training front if future employees are already trained up on the tools, techniques and methodologies of lean and six sigma. Amitava Mitra (2004), Associate Dean and Professor in the College of Business at Auburn University, argues that for companies to survive, they need employees who can continuously improve their products and services, and that academic institutions have both the means and responsibility to train these personnel because they are "a central system of knowledge research and its dissemination". Many engineering and business students in European universities develop skills in their own area of study, but largely without any formal training to help them integrate the required skills into a holistic problem-solving framework which requires statistical, management and technical skills. The future engineers and managers should pick up a good blend of statistical, technical and leadership skills for tackling business problems in organizations and I strongly believe that six sigma and lean strategies can provide solutions to such problems. What is the best curriculum in the market to teach both lean and six sigma topics in the business and engineering schools? I have noticed that there is no standard curriculum for six sigma at this stage in many top engineering and business schools in Europe. Students may take few hours of lectures or in some cases a module covering both aspects of six sigma and lean. However from a research point of view, it is essential to develop a standard curriculum on lean six sigma (which is an integration of lean and six sigma strategies) in both engineering and business schools. The six sigma programs offered in Arizona State University and Virginia Tech are worth exploring as a good starting point although I feel that both programs have too much emphasis on statistical methods.

Academic institutions have an important role to play in tackling the limitations of six sigma. This section briefly outlines the limitations of six sigma which need the attention of academics in leading engineering and business schools around the world:

- The 1.5 sigma shift resulting in a 3.4 defects per million opportunities widely expounded is a generally accepted assumption for manufacturing processes. The same assumption for service and transactional processes do mot make much sense.

- It is widely accepted that one of the critical success factors for the successful deployment of six sigma is visionary leadership. However leadership styles interact with the culture of a particular country and culture within an organization. I think very little research has been carried out to demonstrate the impact of leadership style and culture on the successful deployment of a six sigma initiative.

- I have noticed that the training contents of six sigma black belt and green belt vary quite significantly from one training provider to another and there is an immense variation from one country to another country. No unified standards and procedures have been accepted so far. 
- The relationship between the cost of poor quality (COPQ) and the sigma quality level (SQL) illustrated in the literature and widely used in many training programs requires more justification. The existing data showing this relationship is based on experience. Empirical research in this area would be really helpful for many practitioners in the forthcoming years.

- The relationship between COPQ and its financial impact in small businesses is an under-researched topic among the academic community. It is rarely observed that small companies take account of quality costs. The link between COPQ and sigma quality level across different industrial sectors needs further research.

- Project selection and its prioritisation is one of the most critical success factors (CSFs) of a six sigma initiative. Any failure in project execution at the early stage of a six sigma program will result in the approach being regarded as another "flavour of the month". From the perspective of a small or medium-sized enterprise (SME), it is imperative to develop a project selection methodology to identify the high-impact projects at the initial stage of programme.

- Forecasting and time series methods are usually not addressed in six sigma training programs. Forecasting is perhaps the most important analytic tool in many business operations, because forecasts provide the information on which many management decisions are made. Without accurate and timely forecasts, planning, scheduling and procurement decisions can be seriously in error leading to waste and inefficiency throughout the supply chain.

- Is the five sigma wall approach used in design for six sigma literature a valid assumption? Can this five sigma wall approach be used for service and transactional processes?

- Research has shown that the current and future focus of six sigma will be on the financial and healthcare sectors, industries that are major contributors to the GDP of any developed economy. In the authors' opinion, the application of six sigma in health care and financial service industries will continue to grow, especially here in Europe over the next five years or so. A roadmap or a framework for six sigma implementation is highly desirable that would allow the health and financial sectors to deliver a truly high-class service to their customers.

- Last, but not least, six sigma will survive only when it has a strong theoretical underpinning and linkage with other management theory. The theory of six sigma is lacking and there is no basis for research other than "best practice" studies (Linderman et al., 2003). Thus, the academic fraternity has an important role to play in bridging the gap in the theory of six sigma and understanding the mechanisms by which six sigma influences business processes and performance.

\section{References}

Linderman, K., Schroeder, R.G., Zaheer, S. and Choo, A.S. (2003), "Six sigma: a goal-theoretic perspective”, Journal of Operations Management, Vol. 21, pp. 193-203.

Mitra, A. (2004), "Six sigma education: a critical role for academia", The TQM Magazine, Vol. 16 No. 4, pp. 293-302. 
IJPPM

57,1

110

\section{Further reading}

Antony, J. (2004), "Some pros and cons of six sigma: an academic perspective", The TQM Magazine, Vol. 16 No. 4, pp. 303-6.

\section{About the author}

Jiju Antony, Director of the Centre for Research in Six Sigma and Process Excellence (CRISSPE), based at the University of Strathclyde, in his ten years of research career has published more than 150 refereed papers and four textbooks. Professor Antony has been invited several times as a keynote speaker to national conferences on six sigma in China, South Africa, The Netherlands, India, Greece, New Zealand, South Africa and Poland. Professor Antony has also chaired the First and Second International Conferences on Six Sigma and First and Second International Workshops on Design for Six Sigma. He has been considered for Who's Who in the World and has been published in 2006 Edition as an acknowledgement of his contribution to the field of Quality Management \& Six Sigma. The recent work of the Professor Antony includes collaborations with organisations such as Thales Optronics Ltd., Rolls-Royce, Bosch, Nokia, GE Domestic Appliances, Scottish Widow, NHS Ayr and Aaran, Resolution Asset Management, Kwit Fit Financial Services, Clydesdale Bank etc. in the development of Six Sigma, Lean and Continuous Improvement programmes within these organisations. He is on the Editorial Board of over eight International Journals and a regular reviewer of five leading International Journals in Quality, Operations and Production Management. He can be contacted at: jiju.antony@ strath.ac.uk 